\title{
Study on Particle-Size Process on Internal Erosion of Grap-Graded Soil-Rock Mixtures of Different Fine Contents
}

\author{
Zhilin $\mathrm{Cao}^{1}$, Weichen $\mathrm{Sun}^{1}$, qiang $\mathrm{xie}^{1}$, Zhihui $\mathrm{Wu}^{1}$, Xiang $\mathrm{Fu}^{2}$, and Dalang Tian ${ }^{1}$ \\ ${ }^{1}$ Chongqing University \\ ${ }^{2}$ Chongqing Jiaotong University
}

October 28, 2021

\begin{abstract}
Soil-rock mixtures are widely encountered in geotechnical engineering projects. The instability and failure mechanism of grapgraded soil-rock mixtures under rainfall conditions has always been the focus of geological disaster research. To deeply explore the mechanism of seepage deformation of soil-rock mixtures, an indoor physical permeability test that considers soil-rock mixtures with different fine contents was conducted, and a particle-scale numerical simulation test of the permeability evolution was carried out using the coupling model of PFC3D and ABAQUS. The test results showed that the spatial distribution of fine particle loss along the height direction could be divided into three areas: top loss, middle uniform, and bottom loss area. The "island" effect of coarse particles, which is caused by excessive fine content and makes the fine particles bear more load, was eliminated with the loss of fine particles. In this preset working condition of coarse and fine particle diameters, setting FC to $35 \%$ may be the best way to fill the voids between the coarse particles. Particle migration leads to a change in the load-bearing skeleton structure, thereby causing seepage deformation. Therefore, the particle-scale numerical test method can better reproduce the seepage deformation process of grap-graded soil-rock mixtures.
\end{abstract}

\section{Study on Particle-Size Process on Internal Erosion of Grap-Graded Soil-Rock Mixtures of Different Fine Contents}

\section{Zhilin Cao ${ }^{1}$, Weichen Sun ${ }^{1}$, Qiang $\mathrm{Xie}^{\mathbf{1}^{*}}$, Zhihui $\mathbf{W u}^{1}$, Xiang Fu ${ }^{2}$, Dalang Tian ${ }^{1}$}

${ }^{1}$ School of Civil Engineering, Chongqing University, Chongqing, China ${ }^{2}$ College of River and Ocean Engineering, Chongqing Jiaotong University, Chongqing, China

\section{Corresponding Author :}

address:School of Civil Engineering, Chongqing University, Chongqing, China

Email: xieqiang2000@163.com

\section{Abstract}

Soil-rock mixtures are widely encountered in geotechnical engineering projects. The instability and failure mechanism of grap-graded soil-rock mixtures under rainfall conditions has always been the focus of geological disaster research. To deeply explore the mechanism of seepage deformation of soil-rock mixtures, an indoor physical permeability test that considers soil-rock mixtures with different fine contents was conducted, and a particle-scale numerical simulation test of the permeability evolution was carried out using the coupling model of PFC3D and ABAQUS. The test results showed that the spatial distribution of fine particle loss along the height direction could be divided into three areas: top loss, middle uniform, and bottom loss area. The "island" effect of coarse particles, which is caused by excessive fine content and makes the fine particles bear more load, was eliminated with the loss of fine particles. In this preset working condition of 
coarse and fine particle diameters, setting FC to $35 \%$ may be the best way to fill the voids between the coarse particles. Particle migration leads to a change in the load-bearing skeleton structure, thereby causing seepage deformation. Therefore, the particle-scale numerical test method can better reproduce the seepage deformation process of grap-graded soil-rock mixtures.

\section{Keywords}

Soil-rock mixtures, internal erosion, fines content, solid-fluid interaction, particle skeleton structure

\section{INTRODUCTION}

Soil-rock mixtures consist of rock blocks within soils composed of sand, silt, and clay. The geological origins of soil-rock mixtures vary between landslide, colluvial, alluvial-diluvial, and glacial deposits (Xu et al., 2007), which are widely distributed in the Three Gorges Reservoir area, China (Zhang et al., 2015; Shi et al., 2016). Under the action of rainfall infiltration, landslides, collapses, and other geological disasters can easily occur due to the migration of fine particles in gap-graded soil-rock mixtures (Grosta et al., 1999; Zhang et al., 2011; Johan et al., 2013; Lei et al., 2017; Fan et al., 2020). Therefore, the study of seepage-induced fine particle migration through gap-graded soils is crucial (Cheng et al., 2018; Tian et al., 2020).

Soil-rock mixtures are granular materials that can be constituted in many different ways with different types of intergrain contacts (Thevanayagam et al., 2002). The microstructure and mechanical behaviour of granular materials largely depend on the particles of the constituent materials and the particle size distributions (PSDs). Particles of different sizes exhibit a high degree of force heterogeneity. Skempton et al. (1994) found that fine content (FC) in gap-graded soils affects soil strength. Ouyang et al. (2015) presented experimental investigations on the influence of initial FC on the fabric of soils subjected to internal erosion. Lopez et al. (2016) proposed a case study of a soil structure based on previous empirical observations, which conceptually explained the effects of different components (coarse and fine particles) on the mixture behaviour. Tian et al. (2020) studied the critical FC of natural accumulation soil, beyond which the internal stability of the mix was distinctly altered. Based on the fact that fine particles in soils gradually migrate downwards and lead to subsequent slope failure during rainfall events, Yin et al. (2021) developed a 3D discrete solid-fluid sequentially coupled model to analyse changes in pore structure caused by fine particle migration. However, there are few studies on the micro process and evolution characteristics of fine particle migration of different FCs and the visual description of the infiltration process phenomena.

Owing to advancements in computer technology, numerical simulation methods have been employed to address this limitation and investigate the particle migration process with high precision (Guo and $\mathrm{Yu}, 2017$; Peters et al., 2019; Wang et al., 2020). For the study of gap-graded soils, particle-size numerical test using the CFD-DEM method has become a research trend (Zou et al., 2020; Xiong et al., 2021), as it can enable a deeper understanding of the fine particle migration process and the coupling mechanism between particles and seepage flow. Zou et al. (2013) studied the particle transport mechanism in a base soil-filter system using the CFD-DEM method. Yang et al. (2019) improved the semi-resolved CFD-DEM model for seepageinduced fine particle migration. Cheng et al. (2021) revealed that unresolved CFD-DEM models predict unreasonably high critical hydraulic gradients for suffusion in gap-graded soil columns packed under gravity.

The occurrence of internal erosion of grap-graded soil-rock mixtures is the result of the interaction of water pressure, particle migration, and soil stress state. In this study, a fluid-solid coupled model of internal erosion through the coupling of CFD and DEM was developed to study the coupling effect of water pressure, particle migration, and soil stress state. Moreover, a permeability test for the stability of the gap-graded soil-rock mixtures considering particle loss was conducted to analyse the effect of different FCs, and the numerical simulation results were verified. This study focused on the particle-scale process of the seepage deformation of grap-graded soil-rock mixtures and dynamic changes in load-bearing skeletons with different FCs. This study is helpful in exploring the deformation and failure law of soil-rock mixtures under the condition of rainfall infiltration. 


\section{COUPLED CFD-DEM MODEL}

The coupled CFD-DEM method used in this study included three types of formulation: DEM, CFD, and CFD-DEM coupling formulations. PFC3D was used to solve the particle system at the particle scale, and Newton's law of motion was used to control the particle motion. Moreover, ABAQUS with the porous media seepage theory, Darcy flow model, was used as the CFD solver. The particle-fluid interaction, including the drag and pressure gradient forces, was calculated using the ABAQUS-PFC3D program developed by us. The entire fluid-solid interaction process is illustrated in Fig. 1.

\subsection{Governing Equations of the Particle Phase}

In the fluid-solid coupling method, the behaviour of the particle phase is controlled by Newton's law of motion. In the PFC3D program, the governing equations of the particle phase are given by Eqs. (1) and (2) (Itasca, 2018),

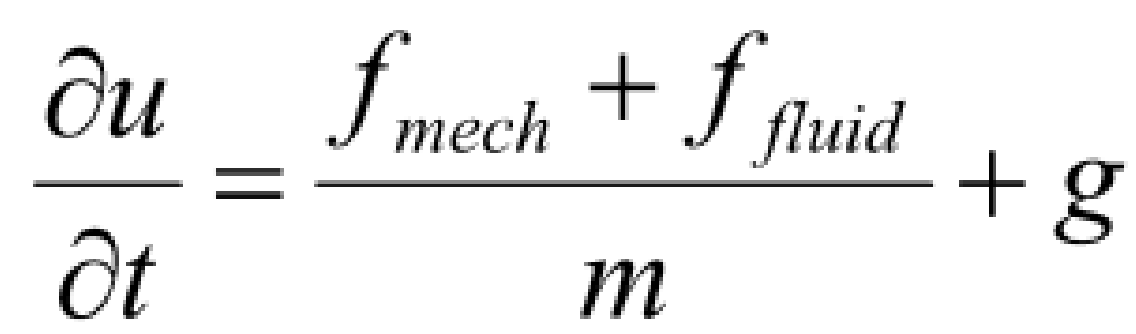

(1)

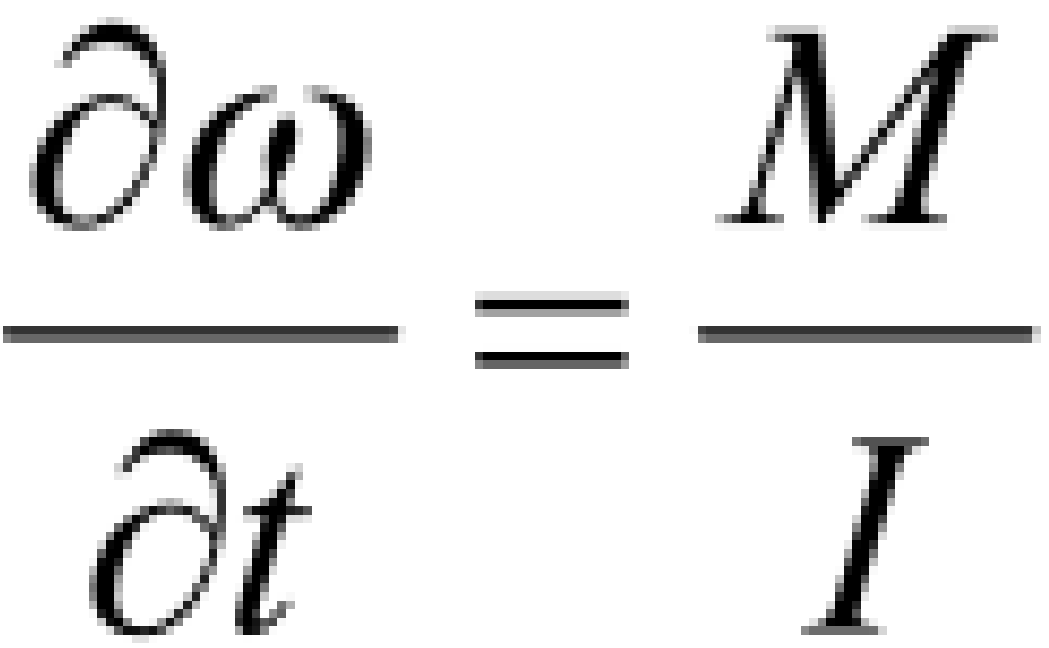

(2)

where $u$ is the particle velocity, $m$ is the particle mass, $f_{\text {fluid }}$ is the total force applied by the fluid on the particle, $f_{\text {mesh }}$ is the sum of additional forces (externally applied forces and contact forces) acting on the particle, $g$ is the acceleration due to gravity, $\omega$ is the particle angular velocity, $I$ is the moment of inertia, and $\mathrm{M}$ is the moment acting on the particle. 


\subsection{Governing Equations of the Fluid Phase}

In the CFD-DEM method, the Darcy fluid model has been proven to be an effective and efficient method for predicting fluid behaviour using an appropriate permeability (Goodarzi et al., 2014; Cui et al., 2016; Tang et al., 2017). The Darcy fluid model was adopted for the fluid flow simulation in this study. The governing equations of the transient fluid flow through a saturated porous media based on the Darcy model and the fluid phase are assumed to be incompressible.

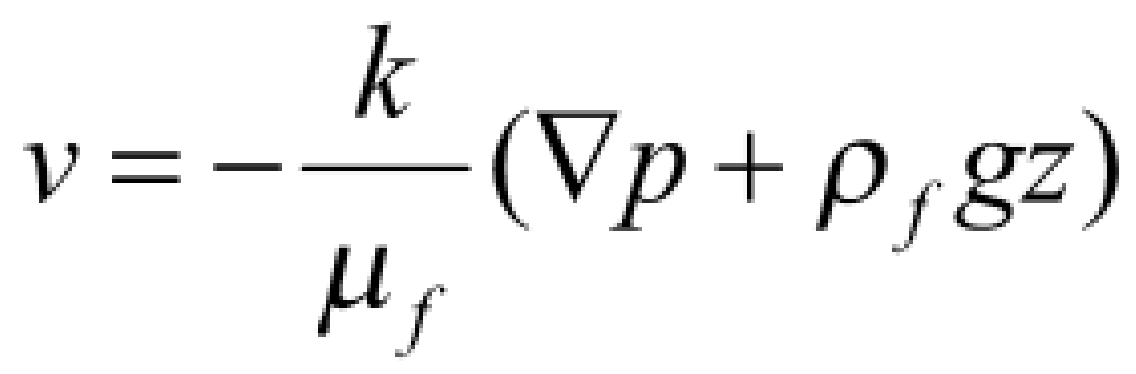

(3)

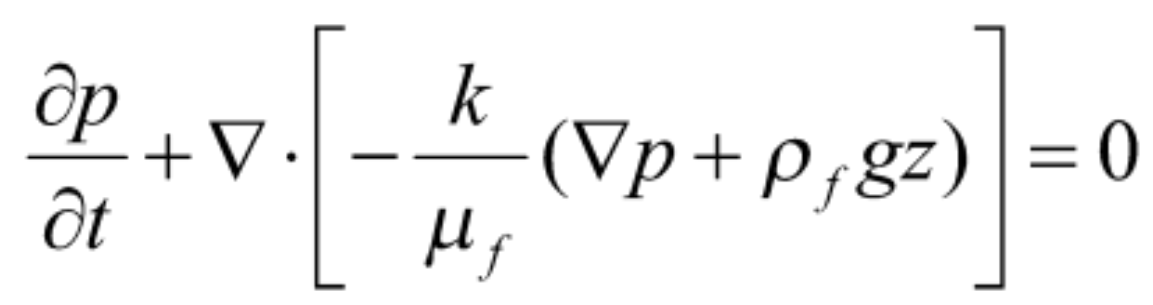

(4)

where $\mathrm{v}$ is the fluid velocity, $\mathrm{k}$ is the matrix permeability, $\mu_{\mathrm{f}}$ is the fluid viscosity, $\mathrm{p}$ is the fluid pressure, $\rho_{\mathrm{f}}$ is the fluid density, $\mathrm{g}$ is the magnitude of gravitational acceleration, and $\mathrm{Z}$ is the position height. Given the boundary conditions, the fluid pressure field can be calculated using Eq. (4), and the corresponding water velocity can be determined using Eq. (3).

\subsection{Fluid-Particle Interaction Force}

The fluid-solid interaction follows the numerical analysis system of the coarse-grid approach (Tsuji et al., 1993), as shown in Fig. 2. In the coarse-grid method, equations describing the fluid flow are solved numerically on a set of elements that are larger than the particles. The force applied by the fluid to the particles (the fluid-particle interaction force), $\mathrm{f}_{\text {fluid }}$, comprises two parts: a drag force and a force due to the fluid pressure gradient, which are given in Eq. (5).

$$
f_{\text {fluid }}=f_{\text {drag }}+\frac{4}{3} \pi r^{3}\left(\nabla p-\rho_{f} g\right)
$$


The drag force exerted by the fluid on the particles is defined individually for each particle. Depending on how the porosity is calculated, a particle may intersect with more than one fluid element. The fluidsolid interaction force is always applied at the particle centroid, and no rotational moment is applied to the particle. The drag force, $\mathrm{f}_{\mathrm{drag}}$, is defined as:

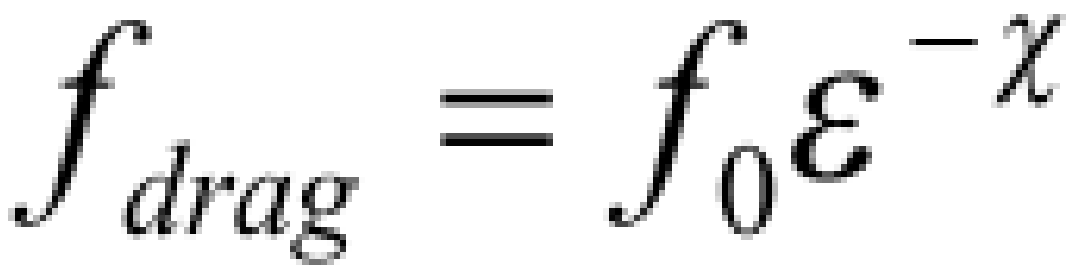

(6)

where $\mathrm{f}_{0}$ is a single-particle drag force given by Eq. (7) and $\varepsilon$ is the porosity of the fluid element where the particle resides. The $\varepsilon^{-\chi}$ term is an empirical factor that accounts for local porosity. This correction term makes the force applicable to both high-porosity and low-porosity systems and for a large range of Reynolds numbers (Difelice et al., 1994; Xu et al., 1997).

$$
f_{0}=\frac{1}{2} C_{d} \rho_{f} \pi r^{2}|u-v|(u-v)
$$

(7)

where $\mathrm{C}_{\mathrm{d}}$ is the drag coefficient, $\rho_{\varphi}$ is the fluid density, $\mathrm{r}$ is the particle radius, $\mathrm{v}$ is the fluid velocity, and $\mathrm{u}$ is the particle velocity.

The drag coefficient is defined as:

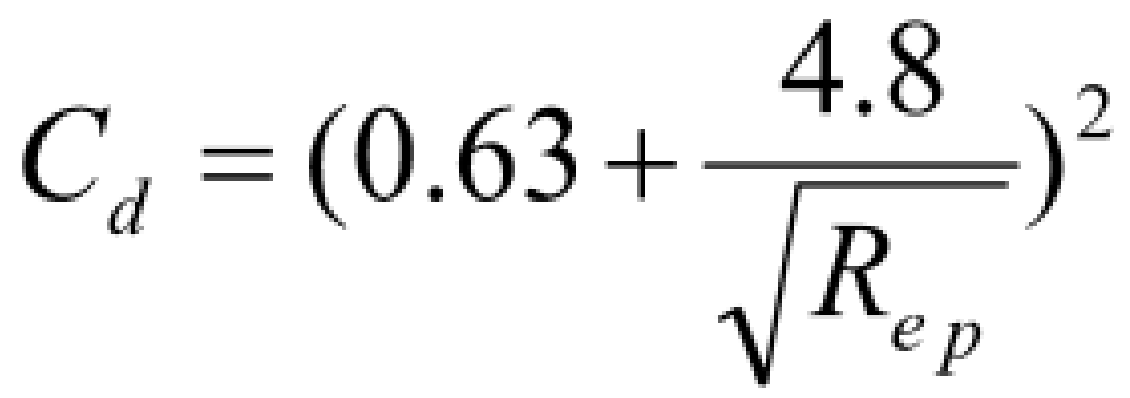

(8)

where $R_{e p}$ is the particle Reynolds number. 
The empirical coefficient $\chi$ is defined as:

$$
\chi=3.7-0.65 \exp \left(-\frac{\left(1.5-\log _{10} R_{e p}\right)^{2}}{2}\right)
$$

(9)

The particle Reynolds number is given as:

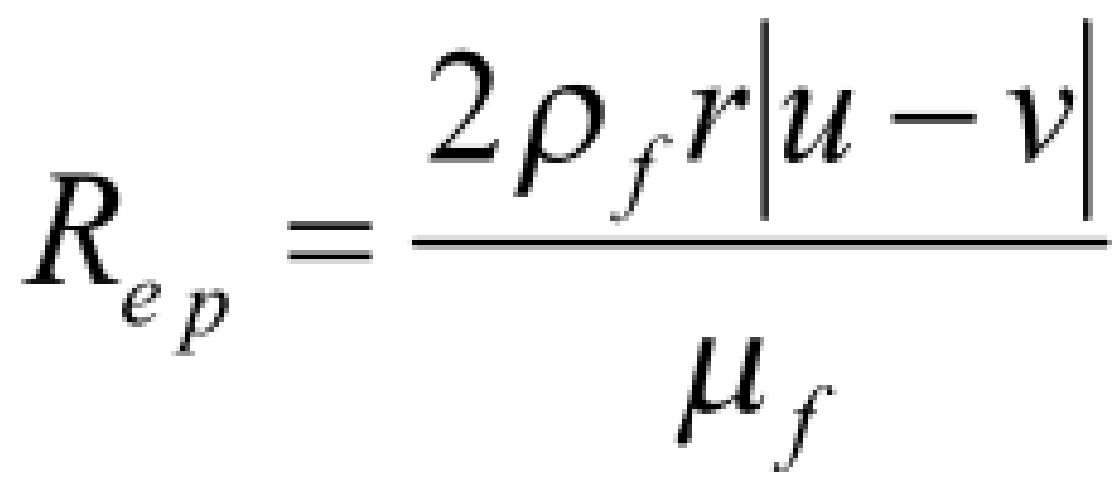

(10)

where $\mu_{\varphi}$ is the fluid viscosity.

The Kozeny-Carman relation (Kozeny et al., 1927; Carman 1939) was used to estimate the permeability. Two-way coupling was accomplished by updating the permeability coefficient information for each fluid element and updating the fluid velocity field of each discrete element. The permeability of each fluid element was calculated from the porosity of the PFC3D model, and the calculation is given by Eq. (11),

$$
k\left(\varepsilon^{i}\right)=\left\{\begin{array}{c}
\frac{1}{36 c} \frac{\left(\varepsilon^{i}\right)^{3}}{\left(1-\varepsilon^{i}\right)^{2}}(2 r)^{2}, \varepsilon^{i} \leq 0.7 \\
K\left(\varepsilon^{i}\right), \varepsilon^{i}>0.7
\end{array}\right.
$$

$(11)$

where $\mathrm{k}$ is the permeability, $\mathrm{r}$ is the radius of the PFC particles, $\mathrm{c}$ is the $\mathrm{K}-\mathrm{C}$ constant, which was 5 in this study, and $\varepsilon^{i}$ is the porosity of each fluid element. The permeability coefficient was taken as the upper limit of porosity, which was $70 \%$. When the porosity of the element exceeded $70 \%$, most particles in the fluid element were washed away, and the permeability coefficient was taken as a fixed value. 


\section{PHYSICAL TEST}

A vertical erosion test device was developed for this study. The device can simulate the action of a constant water head and load on a sample in the saturated state to ensure the formation of a dynamic seepage network in soil-rock mixtures.

\subsection{Device Design}

The set of devices included a sample saturation device, an erosion simulation device with a constant head, a particle collection device, and data collection devices. The erosion simulation device was divided into five layers, which was convenient for analysing the changes in FC at different heights after the test, as shown in Fig. 3.

The sample saturation device was a transparent plexiglass water tank. The water tank was composed of five transparent plexiglass plates with a thickness of $1 \mathrm{~cm}$. The erosion simulation device was composed of five transparent plexiglass cylinders, which could be easily disassembled and assembled. The fifth plexiglass cylinderwas a constant head control part with a height of $25 \mathrm{~cm}$, and an overflow drain was installed $5 \mathrm{~cm}$ away from the top of the fifth cylinder to keep the head height constant at $10 \mathrm{~cm}$ (the global hydraulic gradient, i, was 0.2 ). The five transparent plexiglass cylinders were installed by a flange connection, and they were sealed and impervious during the test.

The height of the first plexiglass cylinder was $25 \mathrm{~cm}$. A perforated plexiglass plate and wire mesh were embedded on the inner wall $15 \mathrm{~cm}$ away from the bottom of the particle collection device to separate the collection and erosion simulation devices (Fig. 3). The perforated plexiglass plate had a diameter of 19.5 $\mathrm{cm}$ and was filled with round holes with a diameter of $1 \mathrm{~cm}$, and the wire mesh had an aperture of $1 \mathrm{~cm}$. The narrow gap between the perforated plate and the erosion simulation device was filled with geotextiles to eliminate the boundary effect of the particles as much as possible. Two circular holes with a diameter of $5 \mathrm{~cm}$ were arranged on relative positions in the pipe wall to form a hydraulic connection between the water tank and the erosion simulation device during the saturation and erosion tests. The two circular holes and the bottom of the erosion particle collection chamber were sealed with non-woven geotextiles, and only water exchange was allowed between the sample and the water tank (Fig. 3).

The data collection devices used in this test included the following: pore water pressure gauge, dial indicator, and DH3816N data acquisition and analysis system. The pore water pressure gauge was installed in each ring of the erosion simulation device, and the gap between the conductor of the pore water pressure gauge and the hole was sealed with waterproof mastic to avoid the formation of a seepage channel (see Fig. 4). Moreover, a perforated plexiglass plate with a diameter of $20 \mathrm{~cm}$ and weight of $1 \mathrm{~kg}$ filled with round holes with a diameter of $1 \mathrm{~cm}$ was placed on the upper surface of the sample. A dial indicator for measuring the displacement was positioned at the centre of the weight to measure the settlement displacement of the sample.

\subsection{Particle Size Distribution}

The research object of this test was soil-rock mixtures with grap-graded PSDs. The particle size at the boundary between the coarse and fine particles was selected according to the British Standard (1990) and the Ministry of Water Resources of the People's Republic of China (1999). At the same time, considering the test operability and data analysis, $2 \mathrm{~mm}$ was chosen as the boundary particle size of the coarse and fine particles. Quartz sand with a particle size of $0.5-2 \mathrm{~mm}$ was selected as the fine particles. Meanwhile, the maximum particle size of the sample should not be greater than 1/5 of the test size (Ministry of Water Resources of the People's Republic of China, 1999). Therefore, sandstone with a particle size of 10-30 mm was selected as the coarse material, which was obtained from a quarry near Chongqing, China. The ratio of the coarse to fine particles was 5:60.

Based on the fine particle content, Vallejo et al. (2001) and Liu (2006) divided the soil skeleton into coarse, coarse-fine, and fine particle skeleton structures. In the coarse-fine particle skeleton structure, the FC was 
approximately 30\%-40\% (Minh et al., 2014; Lopez et al., 2016). Coarse particles act as soil skeletons and bear most of the load, whereas fine particles fill the pores between the coarse particles and transfer part of the effective stress. However, under rainfall conditions, infiltration destroys the strong interaction between the coarse and fine particles, and as the FC decreases, the skeleton structure becomes unstable. Therefore, it is necessary to analyse the changes in the skeleton structure with FC ranging from $30 \%$ to $40 \%$ under the effect of infiltration. In this study, three FCs, $30 \%, 35 \%$, and $40 \%$, were selected to analyse the seepage deformation of grap-graded soil-rock mixtures. The original particle size distribution of the test material is shown in Fig. 5. The specific gravity of the raw-material soil particles was regarded as approximately $2.65 \mathrm{~g} / \mathrm{cm}^{3}$. The height of the filled samples was $50 \mathrm{~cm}$, and the bottom area was $314.16 \mathrm{~cm}^{2}$. Table 1 summarises the relevant parameters of the materials used in this study.

\subsection{Preparation and Test Procedure}

A batch layered preparation method was used to reshape the sample (Bendahmane et al., 2008), and a sample with uniform mixing of coarse and fine particles was obtained. The specific steps are as follows:

1. The total mass of each batch of materials under dry conditions was $2.0 \mathrm{~kg}$, and the corresponding masses of the quartz sand and sandstone were weighed separately according to the different proportions of coarse and fine particles in each test.

2. Water with a slightly lower standard than that of the optimal water content was added into the quartz sand and stirred.

3. According to the set proportion, sandstone was added into the quartz and water mixture and stirred to obtain the final soil-rock mixture. If too many soil-rock mixtures are prepared at once, it is easy to cause a large separation between the fine and coarse particles at this stage.

The soil-rock mixture was poured into the erosion simulation device and stirred several times. Although some fine particles in the first batch passed through the wire mesh into the particle collection device before the test, there was almost no particle loss afterwards, which was also consistent with the test phenomenon of Moffat et al. (2006). The water inlet pipe was close to the inner wall of the water tank to ensure that the water level slowly infiltrated the sample from bottom to top to minimise the impact of seepage force on the stability of the fine particles. The method of static saturation (Ministry of Water Resources of the People's Republic of China, 1999) was adopted to ensure that the sample remained for $12 \mathrm{~h}$. Based on the observation, there were no bubbles visible to the naked eye in the saturated sample.

This test adopted the seepage mode of the constant head $(\mathrm{I}=0.2)$ and constant load $(1.0 \mathrm{~kg})$ and was carried out approximately $2 \mathrm{~h}$ after saturation. When the test was completed, the drain valve at the bottom of the water tank was opened to allow all the water in the tank and erosion simulation device to be discharged. Afterwards, different samples were collected from the five layers of the erosion simulation device and stored separately. After drying and weighing, the distribution changes in each layer were analysed.

\subsection{Test Results}

\subsubsection{Pressure Gradient Variation}

Fig. 6 shows the pressure gradient variation of the five layers in the erosion simulation device during the test, where $\mathrm{i}_{\mathrm{jk}}$ represents the local hydraulic gradient variation between the $\mathrm{j}$-th and $\mathrm{k}$-th pore pressures.

For $\mathrm{FC}=30 \%$ and $35 \%$ in Figs. 6(a) and (b), respectively,

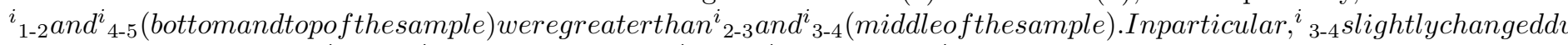
$40 \%$, asshowninFig.6(c), ${ }_{1-2}^{i}$ and $^{i}{ }_{2-3}$ weregreaterthan ${ }_{3-4}{ }_{\text {and }}{ }_{4-5}$. However, ${ }_{3-4}{ }_{3-4}$ increasedafter 1200 sandcontinuedtoexpandat 40\%ismoredif ficulttostabilise, causingtheerosionatthetopof thesampletodeveloptothemiddlepart.

\subsubsection{Changes in Fine Particles in Each Layer}

Fig. 7 shows the changes in fine particles in each layer after the test. It was found that the top change of fine particles in the erosion simulation (first layer) was the largest, followed by the bottom change (fifth layer), 
and then the middle change (second, third, and fourth layers). The greater the $\mathrm{FC}$, the greater the change in fine particles over the entire height. Moreover, the loss of fine particles in the sample with $\mathrm{FC}=40 \%$ in the fifth layer reached a maximum of $5.3 \%$.

After fine particle migration under the action of infiltration, the vertical section of the sample was divided into three areas according to changes in fine particles: top, middle uniform, and bottom loss areas. The loss of fine particles in the top loss area was the largest, followed by the loss in the bottom loss area, and then the loss in the middle uniform area. Because fine particles at the top of the sample were lost to the next layer of the sample without other supplements, the loss of fine particles was the largest. The bottom layer of the sample was located in the downstream section of the seepage channel, and the fine particles were prone to large loss. Meanwhile, the fine particles in the middle of the sample were lost and received supplements from the top of the sample; hence, the change in fine particles was the smallest. Similar phenomena were also observed in the permeability deformation test (Kenney et al., 1985; Marot et al., 2016; Zhong et al., 2018).

It should be mentioned that because the operation error during the test resulted in the successful recording of the dial indicator data of only one of the three samples, there was no comparative analysis of the top settlement of different samples.

\section{PARTICLE-SCALE NUMERICAL TEST}

\subsection{PFC Model}

The numerical test was simplified based on the physical test and the calculation workload. Only ideal discontinuous grap-graded soil-rock mixtures with fine (particle size range of 1-2 mm) and coarse particles (particle size range of $10 \mathrm{~mm}$ ) were considered. The particle shape used in the simulation was spherical, and its influence was not considered. Three types of PSD were selected, and the mass fractions of fine particles in the three gradations were $30 \%, 35 \%$, and $40 \%$. During sample preparation and testing, the gravitational acceleration was set to $9.81 \mathrm{~m} / \mathrm{s}^{2}$, and the direction was vertical and downward.

The numerical test piece was a cylinder with a diameter of $50 \mathrm{~mm}$ and height of $125 \mathrm{~mm}$. The contact model in the PFC adopts a rolling resistance linear model, and Table 2 lists the contact parameters of the PFC particles. In Table 2, a magnitude of $1.5 \mathrm{e} 8 \mathrm{~Pa}$ was selected for the Young's modulus in this study. Although the elastic models of quartz and sandstone are, in reality, greater than 1e9 Pa, Chand et al. (2012) found that a smaller magnitude of Young's modulus does not significantly affect the physical response of the particulate system and also allows for a larger time step, which can considerably save computational resources.

Presently, there are several methods of preparing accumulation particle samples using DEM, such as the falling method (ØREN et al., 2002), pure geometric method (Bagi et al., 2005), radius amplification method (Itasca Consulting Group I, 2004), and layered under compaction method (Jiang et al., 2003). The object of this study belongs to grap-graded PSDs under compaction, that is, natural accumulation. To simulate this stacking state, the sample was prepared based on the works of Huang et al. (2015) and Huang et al. (2020). The specific steps for generating the particle accumulation are as follows:

Stage 1: Initial particles were generated. According to the given soil particle distribution curve, particles were randomly generated in the model by the Monte Carlo method in the wall, which is twice the height of the target model as the initial state (Fig. 8(a)). The initial porosity of the generated particles was set to 0.7, and it was used to control only the number of initial particles.

Stage 2: Stable particle accumulation was obtained after gravitational deposition. By applying gravitational field to the particles, the particles were stably deposited under the action of self-weight, and their porosities were measured. A servo pressure of $100 \mathrm{~Pa}$ was applied on the deposited particle to compact to pressurise the model to the preset sample height. Similar to the physical test, the sample was divided into five layers based on height (Fig. 8(b)). 
Stage 3: The sample was obtained. The lower wall was removed, and a perforated diaphragm with a circular hole diameter of $6 \mathrm{~mm}$ and spacing of $10 \mathrm{~mm}$ was placed (Fig. 8(c)). In this stage, the porosities of the samples with $\mathrm{FC}=30 \%, 35 \%$, and $40 \%$ were $0.39,0.36$, and 0.34 , respectively. As shown in Fig. 8(d), the sample has a coarse-fine particle skeleton structure, and the coarse and fine particles were stressed together.

\subsection{ABAQUS model}

ABAQUS/Standard calculation program was introduced to calculate the seepage in the sample. The shape and size of the ABAQUS calculation grid were consistent with the DEM samples, and there were 120 elements in total, as shown in Fig. 9. As in the physical test, the upper boundary condition of the model was set as the pressure inlet, the lower boundary was set as the pressure outlet, and the surrounding boundary conditions were set as the impermeable wall boundary to simulate one-way seepage. The pressure gradient was set to 0.2 . The fluid parameters used in this study are listed in Table 3. All particle information (including position, velocity, and drag force) and all contact forces and energies within the samples were recorded every $0.1 \mathrm{~s}$ during each suffusion simulation, with a total duration of $20 \mathrm{~s}$. Each coupling interval was approximately $20 \mathrm{~min}$, and with a total of 200-time intervals, it took approximately $2-3$ days on a sample. The calculation was conducted on a computer with Intel I9-9900K and 32 GB RAM.

\section{NUMERICAL RESULTS}

\subsection{Pressure Gradient Variation}

Fig. 10 shows the pressure gradient variations of the different samples during seepage. The fluid element was evenly divided into five parts according to the physical test. In the numerical test of three samples, the pressure gradient of the specimen at different parts of the seepage path was different. This is similar to the phenomenon and law observed in the physical test, where

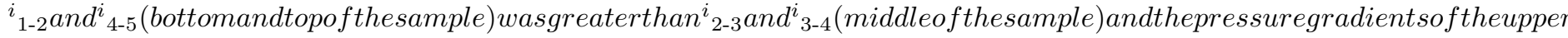
$30 \%$, thephenomenaandlawswereobvious.Inaddition, forthesamplewithFC= $40 \%$, thechangeinpressuregradient ${ }_{3-4}$ wasalsoobvious, whichissimilartothephenomenonobservedinthephysicaltest (Fig.6( $c$

\subsection{Transportation of Fine Particles}

\subsubsection{Macroresponses of the Gap-graded Samples}

Fig. 11 shows the variation in the roof settlement and fine particle loss during the test. Before approximately $3 \mathrm{~s}$, the number of particle losses was inversely proportional to the fine particle content. The loss of fine particles in the sample with $\mathrm{FC}=30 \%$ was the largest, and the roof settlement of the experimental sample with $\mathrm{FC}=40 \%$ was the largest. However, the roof settlement of the sample with $\mathrm{FC}=30 \%$ was greater than that of the sample with $\mathrm{FC}=35 \%$. This may be because the skeleton of the sample with $\mathrm{FC}=30 \%$ was unstable, the loss of fine particles in the first layer was significant, and the roof settlement was also large.

For the sample with $\mathrm{FC}=30 \%$, the roof settlement and particle loss stabilized at approximately 2.5 and 2.7 $\mathrm{s}$, respectively. Meanwhile, for the sample with $\mathrm{FC}=35 \%$, the roof settlement and particle loss stabilized at approximately 3.8 and $7.5 \mathrm{~s}$, respectively. The stability of the roof settlement and particle loss indicated that the load-bearing skeleton was stable. For the sample with $\mathrm{FC}=40 \%$, there was no stabilisation time, and the rate of change of sedimentation and particle loss reduced in $4 \mathrm{~s}$.

\subsubsection{Particle Migration}

Based on the analysis of the seepage failure process of each test, some specific time points were selected for analysis (Fig. 11(b)). Fig. 11 depicts the internal migration of pre-stratified particles at different times, where the black arrow represents the main infiltration channel. The figure shows that the coarse particles moved slightly. 
Before the test, the number of particles lost in the first layer was the highest, as shown in Fig. 12(a). As the test progressed, particles in the second and third layers entered the first layer. Afterwards, particles in the fourth layer penetrated the third layer but did not penetrate the second layer. Under the action of the fluid drag force, almost all the particles in the fifth layer penetrated the fourth layer. Fig. 12(b) is similar to Fig. 12(a). However, because of the finer content of the sample, there were more main infiltration channels than the samples with $\mathrm{FC}=30 \%$ and $35 \%$. After $7.5 \mathrm{~s}$, the particles in the second to fifth layers penetrated the first layer.

To further analyse the loss of fine particles in each layer, the number of fine particles at different heights in the test process was counted. As shown in Fig. 13(a), before approximately $3 \mathrm{~s}$, the particle loss of each layer tended to be stable except for the fifth layer, and at approximately $17 \mathrm{~s}$, the particles in the fourth layer began to enter the third layer. The particle accumulation in the third layer caused the number of particles to increase. Thus, Fig. 13(b) is similar to Fig. 13(a). However, no obvious particle accumulation was observed. In Fig. 13(c), all the particles in the fifth layer were lost, and the particle loss in the other layers was not stable.

Fig. 14 shows the changes in fine particles in each layer after the test. The vertical section of the sample can also be divided into three areas according to changes in the fine particle content: top loss, middle uniform, and bottom loss areas. This phenomenon is similar to that of the physical experiments. By comparing Figs. 13(a)-(c), it was found that fine particles with $\mathrm{FC}=30 \%$ emerged and accumulated in the middle uniform area (second-fourth layers), causing the number of particles to increase. Meanwhile, the number of particles in the middle uniform area with $\mathrm{FC}=35 \%$ slightly changed, whereas the number of particles with $\mathrm{FC}=$ $40 \%$ gradually decreased. This shows that under natural accumulation, the fine particles are $35 \%$ and fill the pores of large particles.

\subsection{Coarse-Fine Particle Skeleton Structure}

\subsubsection{Particle-Particle Contacts}

There are five types of particle contact: fine-fine, coarse-coarse, coarse-fine, coarse-wall, and fine-wall contacts. Owing to the loss of fine particles, the fine-fine and coarse-coarse contacts of grap-graded soilrock mixtures change most significantly during seepage failure. Fig. 15 shows the changes in the fine-fine and coarse-coarse contacts.

From Fig. 15, the number of fine-fine and coarse-coarse contacts of the sample with $\mathrm{FC}=30 \%$ remained stable during the test, indicating that although there was a certain loss of fine particles under this fine particle content, it did not affect the change in the load-bearing skeleton. For the sample with $\mathrm{FC}=35 \%$, before approximately $5 \mathrm{~s}$, the number of fine-fine contacts decreased with the loss of fine particles, whereas the number of coarse-coarse contacts increased, showing that the coarse particles in the load-bearing skeleton gradually bear the load of the lost fine particles. After approximately $5 \mathrm{~s}$, the number of contacts did not change. For the sample with $\mathrm{FC}=40 \%$, the number of fine-fine contacts decreased throughout the test, whereas the number of coarse-coarse contacts increased. At the end of the test, the number of contacts did not remain stable, resulting in the continuous loss of fine particles and the number of fine-fine contacts being less than that of samples with $\mathrm{FC}=30 \%$.

Fig. 16 shows the axial force nephogram of fine-fine and coarse-coarse contacts in the load-bearing skeleton after the test. In Fig. 16(a), the area in which the fine particles accumulate between the pores of the coarse particles is marked in red. It is obvious from the figure that the number of fine-fine contacts in the sample with FC $=35 \%$ was the largest, and the stress distribution was relatively large. In Fig. 16(b), for the sample with $\mathrm{FC}=30 \%$, the force chain of the coarse-coarse contact was more complete from the top to bottom of the sample. For the sample with $\mathrm{FC}=35 \%$, the force chain of the coarse-coarse contact was missing in the middle from the top to bottom of the sample, that is, the dense area of fine particles in Fig. 16(a).

\subsubsection{Strong Force Chain Buckling}


Because of the loss of fine particles, the original load-bearing skeleton collapsed, and a new skeleton eventually formed. The collapse of the original load-bearing skeleton was mainly induced by strong force chain buckling. To further understand the evolution characteristics of the packing of particles of different load-bearing skeletons, the upper and lower parts (the junction of the first and second layers and the junction of the third and fourth layers) in each test were selected, as shown in Fig. 17. The strong force chains and chained particles are marked in red. The contact forces between the particles were larger than the average value. Fig. 18 shows the evolution characteristics of the force chain for samples with different FCs at the selected strong force chains. For ease of display, the particles were reduced once.

In Fig. 18(a), the axial force decreased in the initial 1 and $2 \mathrm{~s}$ of the samples with $\mathrm{FC}=30 \%$ and $\mathrm{FC}=$ $35 \%$, respectively. Afterwards, the fine particles in the fifth layer gradually flowed downwards and became lost. Moreover, the interaction of coarse particles between the fourth and fifth layers became increasingly obvious, and the strength of the force chain continuously increased. The samples with $\mathrm{FC}=30 \%$ and $35 \%$ remained stable (approximately 16 and $13 \mathrm{~N}$ ) after $15 \mathrm{~s}$. In the sample with $\mathrm{FC}=40 \%$, there is no force chain between the selected coarse particles in the initial load-bearing structure (the axial force was 0 ). With the development of seepage failure and the loss of fine particles, the axial force of the force chain between the selected coarse particles increased. After $13 \mathrm{~s}$, the axial force remained relatively stable, that is, 16-18 N.

In Fig. 18(b), the axial force decreased in the initial 2 and $4 \mathrm{~s}$ of the samples with $\mathrm{FC}=30 \%$ and $35 \%$, respectively. Subsequently, the axial force remained stable. The time was the same as the stable time of particle loss in Fig. 11(b), indicating that the loss of fine particles stopped and the load-bearing structure of the skeleton remained stable. In the sample with $\mathrm{FC}=40 \%$, the evolution was the same as that in Fig. $18(\mathrm{a})$. After $13 \mathrm{~s}$, the axial force remained relatively stable, that is, 26-28 N.

\section{DISCUSSION}

The relative content of fine particles is the key property affecting stress transfer through grap-graded granular materials. The selected FC in this test was $30 \%-40 \%$, which is a coarse-fine particle skeleton structure. The sample with $\mathrm{FC}=30 \%$ tended to have a coarse particle skeleton structure (fine particles underfilled the voids between the coarse particles), whereas the sample with $\mathrm{FC}=40 \%$ tended to have a fine particle skeleton structure (fine particles overfilled the voids between the coarse particles).

Under the action of vertical infiltration and gravity, the change in pressure gradient in the middle area was less than that in the upper and lower areas (Fig. 10). However, as the FC increased, the pressure gradient in the middle area changed considerably. Because fine particles play an important role in the load-bearing structure, if the fine particles are dragged and migrated, the structure will change significantly, causing the pressure gradient to change with time.

Fine particles were lost at the top and bottom of the three samples; however, as the FC increased, the particles in the middle soil changed from a certain accumulation to stability to particle loss (Figs. 12 and 13). Fine particles reasonably fill the voids between coarse particles and can maintain better stability under the action of the same infiltration force. Obviously, the finer the particles, the greater the force shared by the fine particles. Therefore, in the process of fine particle loss, the samples with FC $=30 \%$ and $35 \%$ were relatively more stable during the test process. For the sample with $\mathrm{FC}=35 \%$, fine particles bore more load contribution (with a finer particle contact number, as shown in Fig. 16(a)). For the samples with FC = $40 \%$, the initial contact force of the strong link was 0 (Fig. 18), which indicates that there was poor contact between the coarse particles such that the coarse particles became an "island" and only a part of the fine particles around the coarse particles bore the load. Meanwhile, the coarse particles bore more load with the loss of fine particles.

By comparing the phenomena and results of the physical and numerical tests, there is a high similarity in the variation process of the pressure gradient and fine particles in different layers. This shows that the numerical model can better reproduce meso phenomena such as particle migration, permeability evolution, 
and particle recombination in the physical test. The coupling model of PFC3D and ABAQUS can be used as an effective means of studying the mechanism of seepage deformation. However, owing to the defect in calculation efficiency of the numerical software, the method needs to be further improved to reflect the irregular characteristics of particles and the influence of micro disturbances in real situations through GPU/CPU parallel technology.

\section{CONCLUSIONS}

In this study, a permeability test for the stability of gap-graded soil-rock mixtures considering particle loss was conducted, and the physical process of seepage deformation of soil-rock mixtures with different FCs was numerically simulated using the coupling model of PFC3D and ABAQUS. The results showed that this coupling model has a good effect on the simulation of the particle-scale movement under seepage. Particle migration causes a change in the soil particle structure and also induces seepage deformation. Hence, the key concluding remarks are as follows:

1. During the seepage process, fine particle loss occurred at different sample heights. After seepage, the spatial distribution of fine particle loss along the height direction can be divided into three areas: top, middle uniform, and bottom loss areas. The pressure gradient in the top loss area was smaller than that in the bottom loss area during the test.

2. The "island" effect of coarse particles, which is caused by excessive fine content and makes the fine particles bear more load, was eliminated with the loss of fine particles. The fine particle content remained relatively stable under the actions of infiltration and vertical gravity. In this preset working condition of coarse and fine particle diameters, setting FC to $35 \%$ may be the best way to fill the voids between the coarse particles.

3. The change processes of the pressure gradient, transportation of fine particles, and the load-bearing structure were recorded, which clearly and intuitively expresses the migration trend of particles in the seepage process. Moreover, the numerical simulation results were highly consistent with the physical test results. This shows that the coupling model of PFC3D and ABAQUS can capture both micro- and macro-characteristics of particles and fluids and has practical significance in simulating the particlescale seepage deformation process of grap-graded soil-rock mixtures.

\section{DECLARATION OF CONFLICTING INTERESTS}

The author(s) declared no potential conflicts of interest with respect to the research, authorship, and/or publication of this article.

\section{ACKNOWLEDGMENTS}

The author(s) disclosed receipt of the following financial support for the research, authorship, and/or publication of this article: This paper gets its funding from projects (Grant No. CYB21031) supported by the graduate research and innovation foundation of Chongqing, China; (LNTCCMA-20200103; LNTCCMA20210107) supported by the Key Laboratory of New Technology for Construction of Cities in Mountain Area. The authors wish to acknowledge these supports.

\section{REFERENCES}

Bagi K (2005) An algorithm to generate random dense arrangements for discrete element simulations of granular assemblies. Granular Matter 7(1), 31-43.

Bendahmane F, Marot D and Alexis A (2008) Experimental parametric study of suffusion and backward erosion. Journal of geotechnical and geoenvironmental engineering 134(1), 57-67. 
BSI (1990). BS1377:1990: Methods of test for soils for civil engineering purposes, Part 1: General requirements and sample preparation.

British: Authority of the Board of BSI Press.

Carman PC (1939) Permeability of saturated sands, soils and clays. The Journal of Agricultural Science 29(2), 263-273.

Chand R, Khaskheli MA, Qadir A, et al. (2012) Discrete particle simulation of radial segregation in horizontally rotating drum: Effects of drum-length and non-rotating end-plates. Physica A-Statistical Mechanics and Its Applications 391(20), 4590-4596.

Cheng K, Wang Y and Yang Q (2018) A semi-resolved CFD-DEM model for seepage-induced fine particle migration in gap-graded soils. Computers and Geotechnics 100, 30-51.

Cheng K, Zhang C, Peng K, et al. (2021) Un-resolved CFD-DEM method: an insight into its limitations in the modelling of suffusion in gap-graded soils. Powder Technology 381: 520-538.

Cui Y, Nouri A, Chan D, Rahmati E (2016) A new approach to DEM simulation of sand production. $J$ Petrol Sci Eng 147, 56-67.

Difelice, R (1994) The voidage function for fluid-particle interaction systems. Int. J. Multiphase Flow 20(1), 153-159.

Fan SY, Song ZP, Zhang YW, et al. (2020) Case Study of the Effect of Rainfall Infiltration on a Tunnel Underlying the Roadbed Slope with Weak Inter-Layer. KSCE Journal of Civil Engineering 24(5), 1607-1619.

Goodarzi M Kwok CY and Tham LG (2014) A continuum-discrete model using Dacry's Law: formulation and verification. Int J Numer Anal Meth Geomech 29(3), 327-342.

Grosta G and Prisco C (1999) On slope instability induced by seepage erosion. Canadian Geotechnical Journal 36 (6), 1056-1073.

Guo Y and Yu XB (2017) Comparison of the implementation of three common types of coupled CFD-DEM model for simulating soil surface erosion.International Journal of Multiphase Flow 91, 89-100.

Huang QF, Zhan ML, Sheng JC, et al. (2015). Numerical method to generate granular assembly with any desired relative density based on DEM.Chinese Journal of Geotechnical Engineering 37(03), 537-543.

Huang Y, Luo YL and Zhang XG. (2020). Numerical method to generate particle packages of internally unstable soils with arbitrary relative density. Water resources and power 38(04), 126-129.

Itasca Consulting Group I. (2004) User's manual: PFC3D-particle flow code in 3 dimensions. Minneapolis: Itasca Consulting Group .

Itasca Consulting Group Inc, 2018. PFC3D 5.00. Documentation.Minneapolis: Itasca Consulting Group Inc

Jiang MJ, Konrad JM and Leroueil S (2003) An efficient technique for generating homogeneous specimens for DEM studies. Computers and geotechnics 30(7), 579-597.

Jiang ZM, Yuan T, Liu DQ, et al. (2018). Mesoscopic numerical tests on seepage failure characteristics of coarse grained soils. Chinese Journal of Geotechnical Engineering 40(4), 752-758. (in Chinese)

Johan V and Zou QP (2013) Investigation of slope instability induced by seepage and erosion by a particle method. Computers and Geotechnics 48: 9-20.

Kenney TC and Lau D (1985) Internal stability of granular filters. Can Geotech J 22(2), 215-225.

Kozeny J (1927) Ueber kapillare Leitung des Wassers im Boden.Sitzungsber Akad. Wiss, Wien 136(2a), 271-306. 
Lei XQ, Yang ZJ, He S, et al. (2017) Numerical investigation of rainfall-induced fines migration and its influences on slope stability.Acta Geotech 12, 1431-1446.

Liu J (2006) Seepage control of earth-rock dams theoretical basis.Beijing: Chian Water E Power Press . (in Chinese)

Liu YJ, Wang LZ, Hong Y, et al. (2020) A coupled CFD-DEM investigation of suffusion of gap graded soil: Coupling effect of confining pressure and fines content. International Journal for Numerical and Analytical Methods in Geomechanics 44(18), 2473-2500.

Lopez R, De F, Silfwerbrand J, et al. (2016) Force transmission and soil fabric of binary granular mixturese. Geotechnique 66(7), 578-583.

Marot DA, Rochim HH, et al. (2016) Assessing the susceptibility of gap graded soils to internal erosion:proposition of a new experimental methodology. Natural. Hazards 83(1), 365-388.

Minh NH, Cheng YP and Thornton C (2014) Strong force networks in granular mixtures. Granular Matter 16(1), 69-78.

Ministry of Water Resources of the People's Republic of China (1999). GB/T 50123-1999. China Planning Press .

Mitchell JK and Soga K (2005) Fundamentals of Soil Behavior. New York: John Wiley E3 Sons, 2005.

Moffat R, Ricardo A, Fannin, et al. (2006) A large permeameter for study of internal stability in cohesionless soils. Geotechnical Testing Journal 29(4), 273-279.

Oren P, Bakke S (2002) Process based reconstruction of sandstones and prediction of transport properties. Transport in Porous Media46(2/3), 311-343.

Ouyang M and Takahashi A (2015) Influence of initial fines content on fabric of soils subjected to internal erosion. Canadian Geotechnical Journal 53(2), 1360-1361.

Peters B, Baniasadi M, Baniasadi M, et al. (2019) XDEM multi-physics and multi-scale simulation technology: Review of DEM-CFD coupling, methodology and engineering applications - ScienceDirect.Particuology 44, 176-193.

Shi DM, Wang WL, Jiang, GY, et al. (2016) Effects of disturbed landforms on the soil water retention function during urbanization process in the Three Gorges Reservoir Region, China. Catena 144: 84-93.

Skempton AW and Brogan JM (1994) Experiments on piping in sandy gravels. Geotechnique 44(3), 449-460.

Tang Y, Chan DH, Zhu DZ (2017) A coupled discrete element model for the simulation of soil and water flow through an orifice.International Journal for Numerical and Analytical Methods in Geomechanics 41(14), 1477-1493.

Thevanayagam S, Shenthan T, Mohan S, et al. (2002) Undrained fragility of clean sands, silty sands, and sandy silts. Journal of Geotechnical and Geoenvironmental Engineering 128(10), 849-859.

Tian DL, Xie Q, Fu X, et al. (2020) Experimental study on the effect of fine contents on internal erosion in natural soil deposits.Bulletin of Engineering Geology and the Environment 79, 4135-4150.

Tsuji Y, Kawaguchi T and Tanaka T (1993) Discrete particle simulation of two-dimensional fluidized bed. Powder Technol 77, 79-87.

Vallejo LE (2001) Interpretation of the limits in shear strength in binary granular mixtures. Canadian Geotechnical Journal 38(5), 1097-1104.

Wang Y, Chai JR, Xu ZG, et al. (2020) Numerical Simulation of the Fluid-Solid Coupling Mechanism of Internal Erosion in Granular Soil. Water 12, 137. 
Xiong H, Yin ZY, Zhao JD dong, et al. (2021) Investigating the effect of flow direction on suffusion and its impacts on gap-graded granular soils. Acta Geotechnica 16, 399-419.

Xu BH and Yu AB (1997) Numerical simulation of the gas-solid flow in a fluidized bed by combining discrete particle method with computational fluid dynamics. Chemical Engineering Science 52(16), 2785-2809.

Xu WJ, Hu RL and Tan RJ (2007) Some geomechanical properties of soil-rock mixtures in the Hutiao Gorge area, China. Geotechnique57(3), 255-264.

Yang Q, Cheng K, Wang, Y, et al. (2019) Improvement of semi-resolved cfd-dem model for seepage-induced fine-particle migration: eliminate limitation on mesh refinement. Computers and Geotechnics 110, 1-18.

Yin Y, Cui Y, Tang Y, et al. (2021) Solid-fluid sequentially coupled simulation of internal erosion of soils due to seepage. Granular Matter 23(2).

Zhang LL, Zhang J and Zhang LM (2011) Stability analysis of rainfall-induced slope failure: A review. Geotechnical Engineering 164(5), 299-316.

Zhang S, Tang HM, Zhan, HB, et al. (2015) Investigation of scale effect of numerical unconfined compression strengths of virtual colluvial-deluvial soil-rock mixture. International Journal of Rock Mechanics and Mining Sciences 77, 208-219.

Zhong CH, LE VT, Bendahamane F, et al. (2018) Investigation of Spatial Scale Effects on Suffusion Susceptibility. Journal of Geotechnical and Geo-environmental Engineering 144(9), 04018067.

Zou YH, Chen C, Zhang LM, et al. (2020) Simulating Progression of Internal Erosion in Gap-Graded Sandy Gravels Using Coupled CFD-DEM.International Journal of Geomechanics 20(1), 04019135.

Zou YH, Chen Q, Chen XQ, et al. (2013) Discrete numerical modeling of particle transport in granular filters. Computers and Geotechnics47, 48-56.

Table 1. Physical properties of the specimen

\begin{tabular}{llllll}
\hline $\begin{array}{l}\text { Number of } \\
\text { samples }\end{array}$ & $d_{10}(\mathrm{~mm})$ & $d_{30}(\mathrm{~mm})$ & $d_{60}(\mathrm{~mm})$ & $C_{\mathrm{u}}\left(\mathrm{d}_{60} / \mathrm{d}_{10}\right)$ & $C_{\mathrm{c}}()$ \\
$\mathrm{FC}=30 \%$ & 0.82 & 3 & 16.12 & 19.75 & 0.68 \\
$\mathrm{FC}=35 \%$ & 0.78 & 1.65 & 15.49 & 19.87 & 0.23 \\
$\mathrm{FC}=40 \%$ & 0.74 & 1.28 & 14.76 & 19.99 & 0.15 \\
\hline
\end{tabular}

Table 2. Calculation parameters of the PFC3D model

\begin{tabular}{lll}
\hline Parameter & $\begin{array}{l}\text { Value } \\
\text { Particle }\end{array}$ & $\begin{array}{l}\text { Value } \\
\text { Wall }\end{array}$ \\
Particle density $\left(\mathrm{kg} / \mathrm{m}^{3}\right)$ & 2630 & - \\
Effective modulus $(\mathrm{Pa})$ & $1.5 \mathrm{e} 8$ & $1.0 \mathrm{e} 9$ \\
Normal-to-shear stiffness ratio & 1.0 & 1.0 \\
Contact friction coefficient & 0.5 & 0.01 \\
Normal critical damping ratio & 0.2 & 0.2 \\
Shear critical damping ratio & 0.2 & 0.2 \\
Rolling resistance coefficient & 0.1 & 0.1 \\
Time step & $1 \mathrm{e}-7$ & - \\
\hline
\end{tabular}

Note: Based on the existing test results, Mitchell et al. (2005) suggested that the friction coefficient of quartz sand is 0.5 . The common anti-rotation coefficient of the particle is taken as 0.1, based on the literature (Liu et al., 2020). 
Table 3. Calculation parameters during the coupling process (Note: the porosity, particle applied force, and drag force are updated every 20 cycles in each coupling interval.)

\begin{tabular}{ll}
\hline Parameter & Value \\
Fluid density $\left(\mathrm{kg} / \mathrm{m}^{3}\right)$ & $1 \mathrm{e} 3$ \\
Fluid dynamic viscosity $(\mathrm{Pa} \cdot \mathrm{s})$ & $1 \mathrm{e}-3$ \\
Gravitational acceleration $(\mathrm{m} / \mathrm{s})$ & 9.8 \\
Pressure gradient difference & 0.2 \\
DEM timestep (s) & $1 \mathrm{e}-7$ \\
Coupling interval (s) & 0.1 \\
CFD update interval & 20 \\
Total simulation time (s) & 200 \\
\hline
\end{tabular}




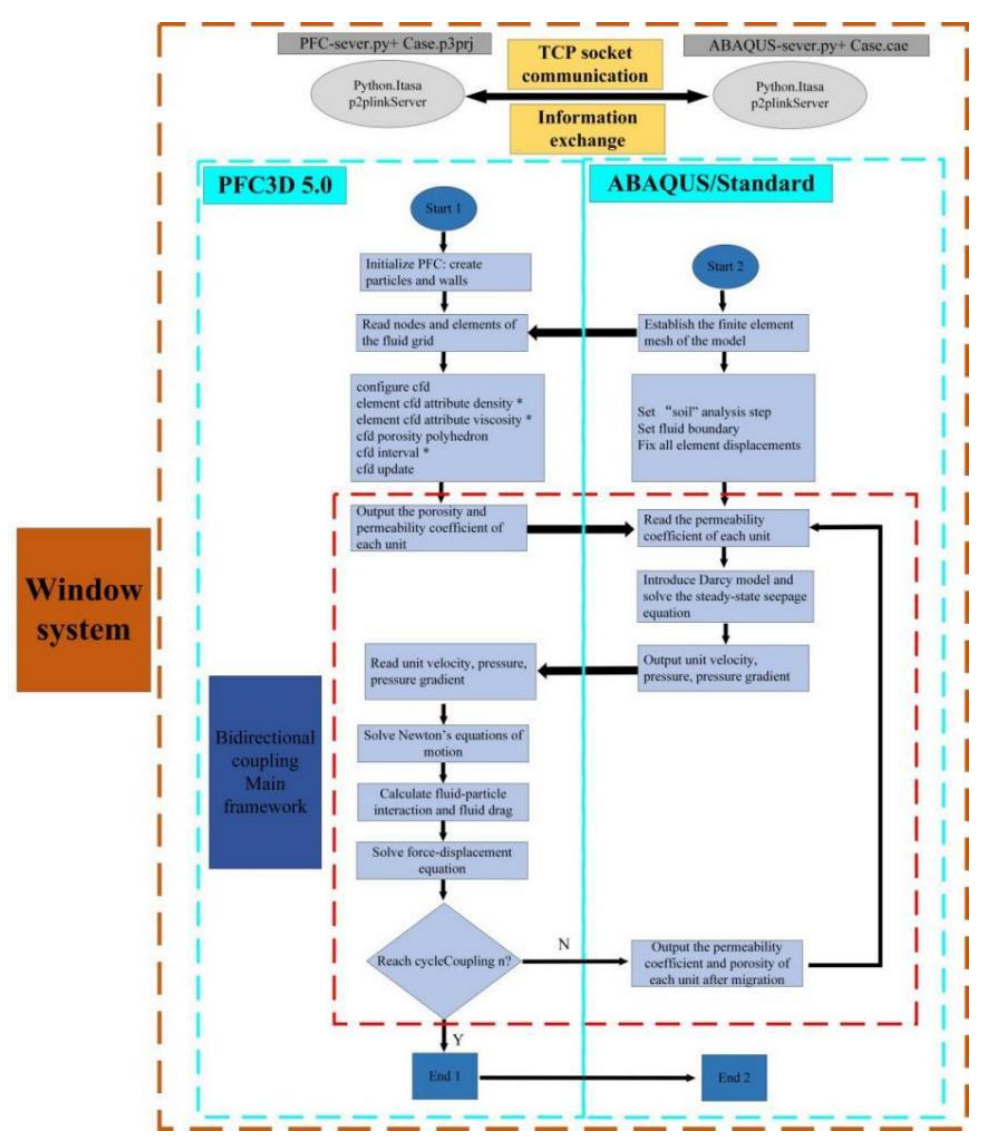

Figure 1 Calculation sequence for the fluid-solid interaction process 


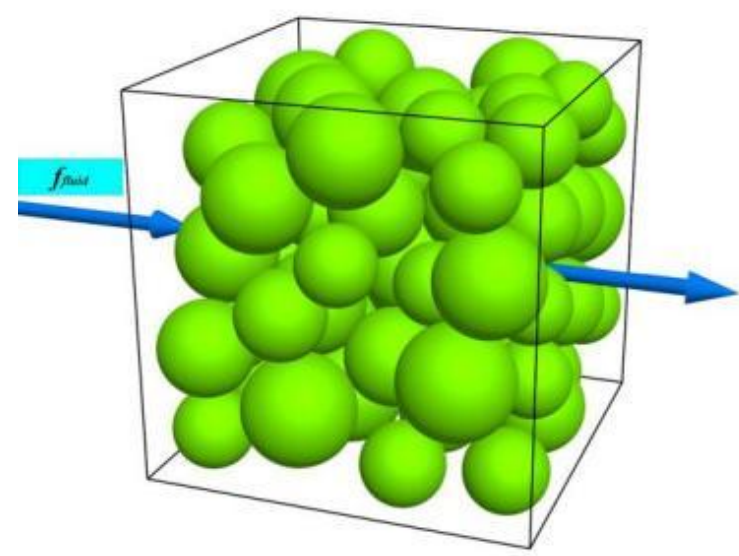

Figure 2 Sketch of the coarse-grid approach 


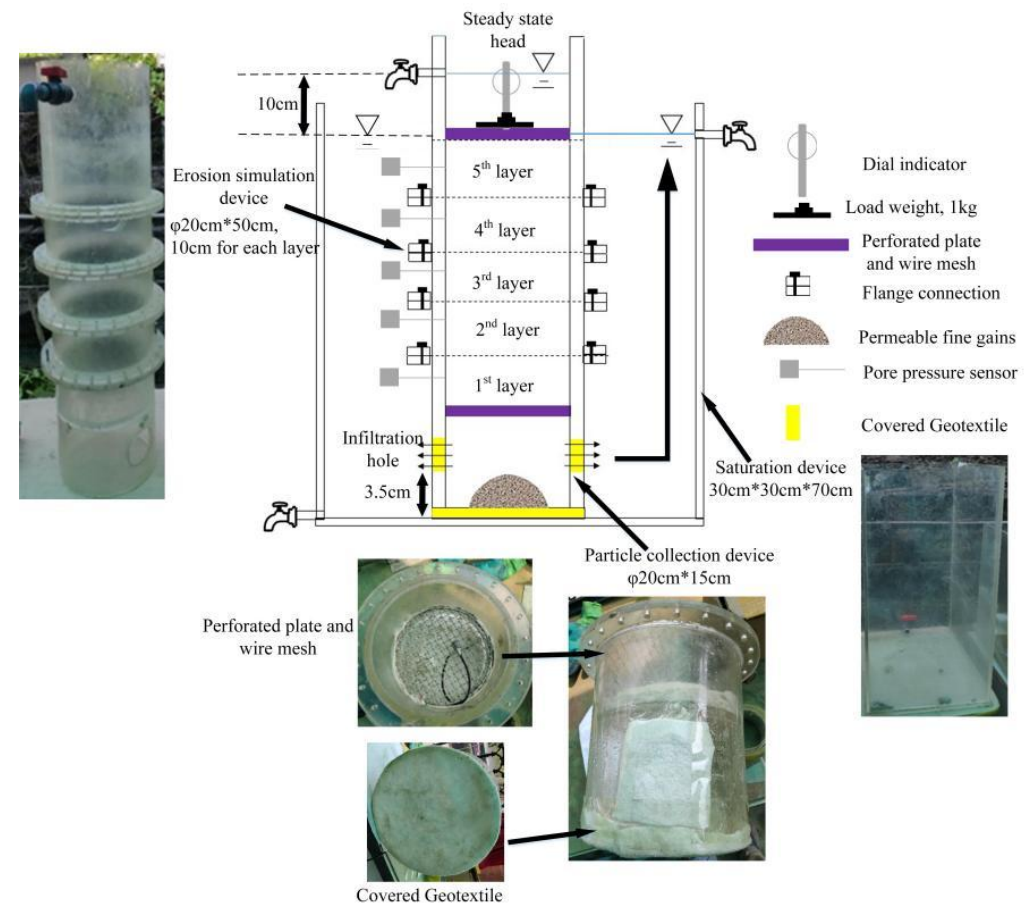

Figure 3 Representation of sample saturation device, erosion simulation device with constant stead, and particle collection device 


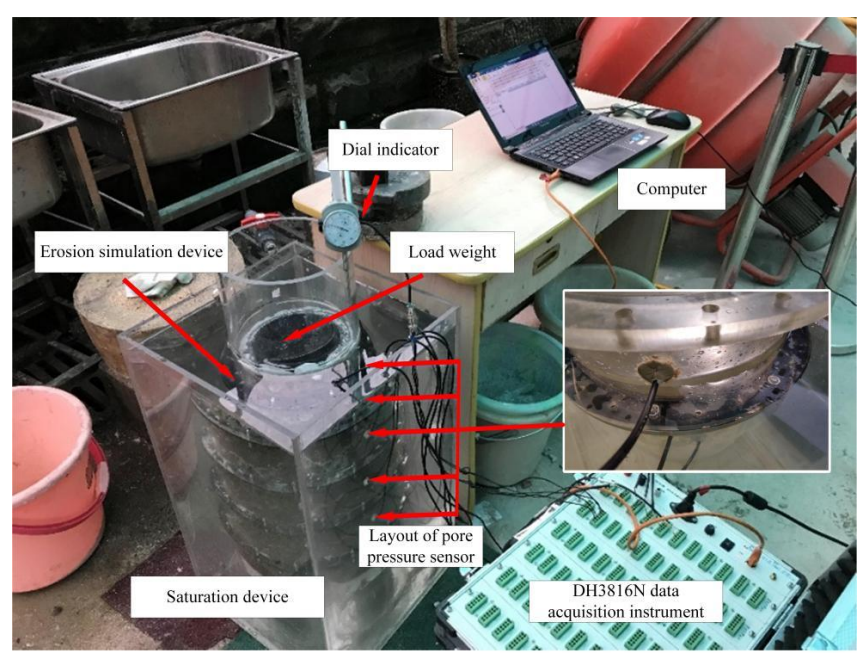

Figure 4 Layout of data collection devices 


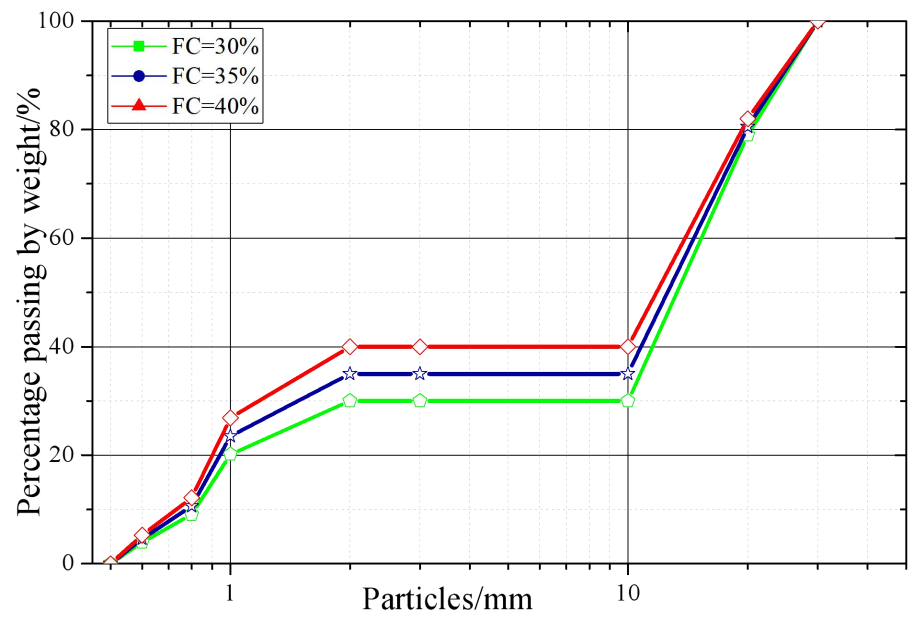

Figure 5 Particle size distribution of the test material 

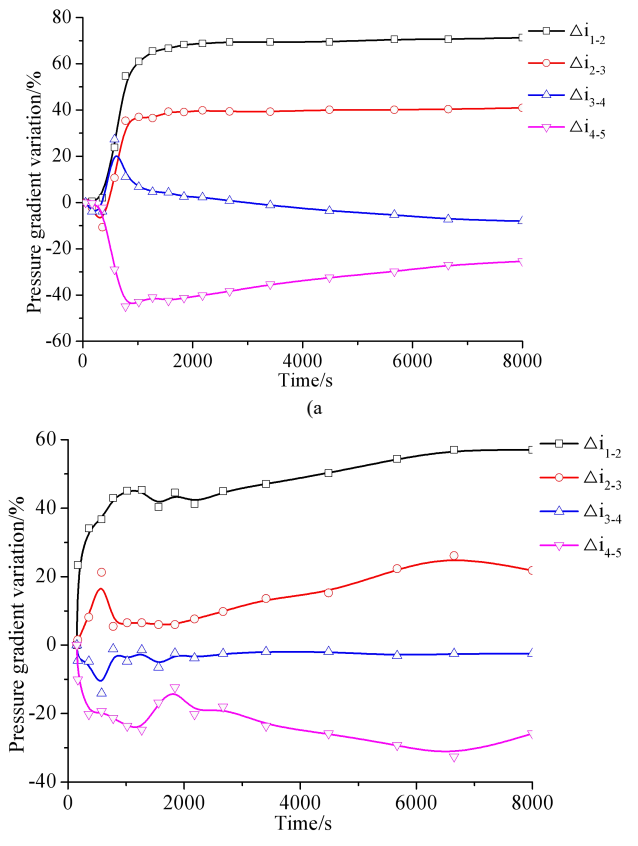

(b)

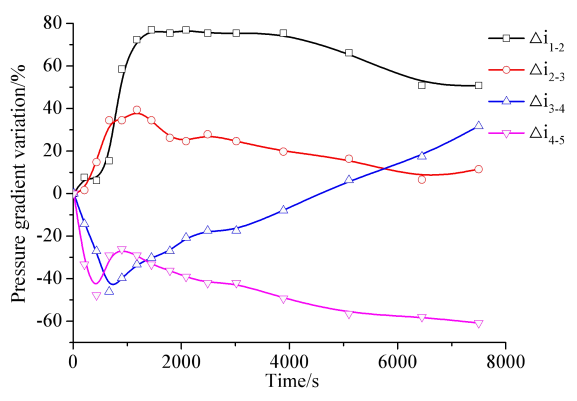

(c)

Figure 6 Pressure gradient variation of samples: (a)FC=30\%; (b) $\mathrm{FC}=35 \%$; (c) $\mathrm{FC}=40 \%$ 


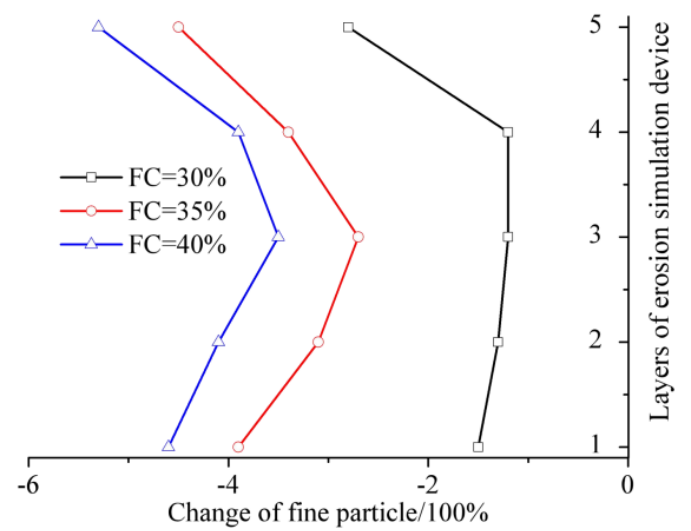

Figure 7 Change of fine particles (note: it is assumed that the total amount of fine particles before the test is $\boldsymbol{m}$ and after the test is $\boldsymbol{m}_{j}$, so the change of fine particles $\left.=\left(\boldsymbol{m}-\boldsymbol{m}_{j}\right) / \boldsymbol{m}^{*} 100 \%\right)$ 

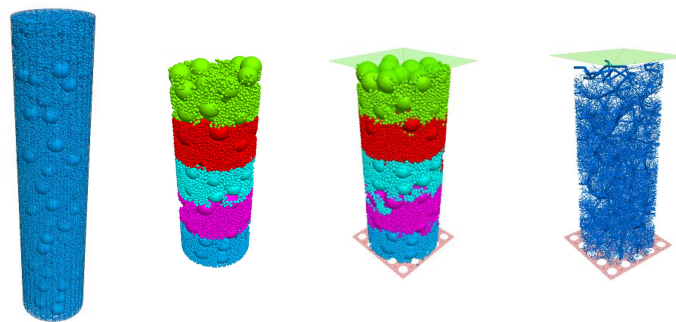

(a)

(b)

(c)

(d)

Figure 8 Model setup of the sample with $\mathrm{FC}=35 \%$ : (a) particles in the stage 1; (b) particles in the stage 2; (c) particles in the stage 3; (d) contacts in the the stage 3 
Figure 9 Fluid computing element

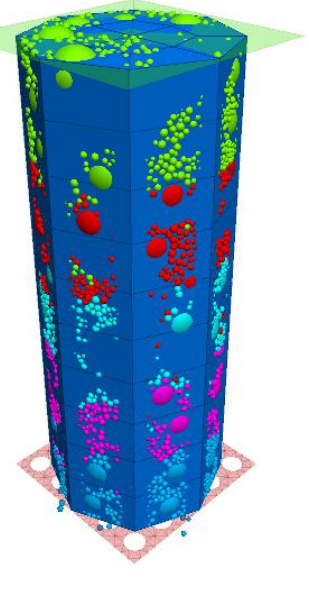




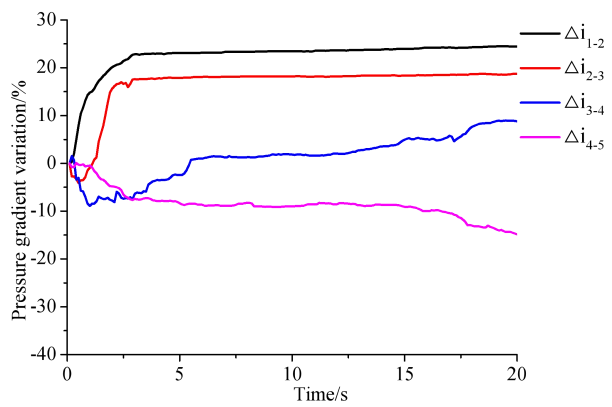

(a)

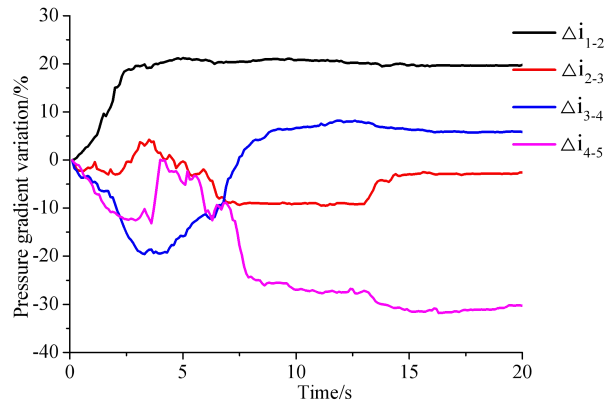

(b)

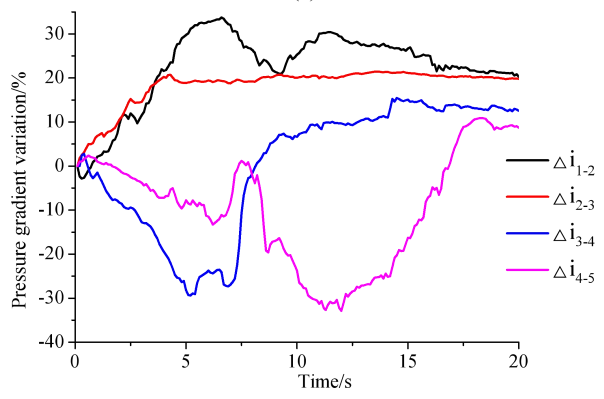

(c)

Figure 10 Pressure gradient variation of numerical results: (a) $\mathrm{FC}=30 \%$; (b) $\mathrm{FC}=35 \%$; (c) $\mathrm{FC}=40 \%$ 


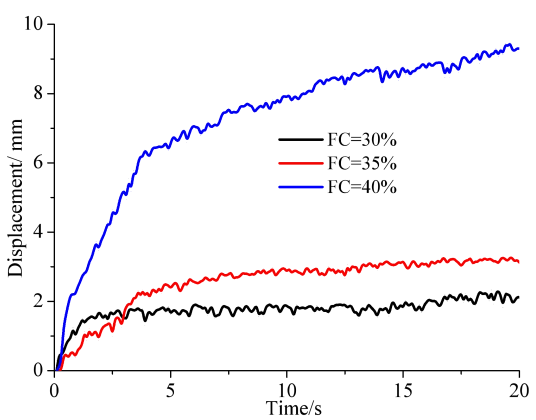

(a)

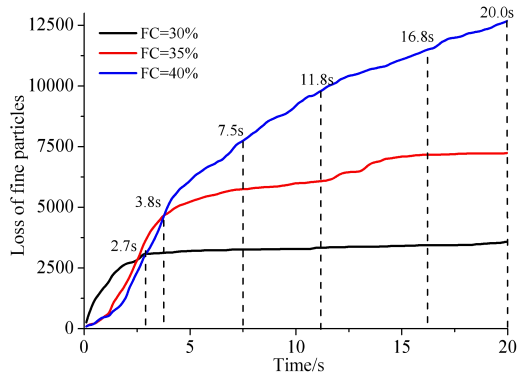

(b)

Figure 11 Macroresponses of the gap-graded samples of different FC: (a)Roof subsidence evolution; (b) Evolution of fine particle loss

\section{Hosted file}

Figure 12 Migration of particles in each layer of samples (a) $\mathrm{FC}=30 \%$; (b) $\mathrm{FC}=35 \%$; (c) $\mathrm{FC}=40 \%$.pdf available at https://authorea.com/users/443430/articles/543410-study-on-particle-sizeprocess-on-internal-erosion-of-grap-graded-soil-rock-mixtures-of-different-fine-contents 

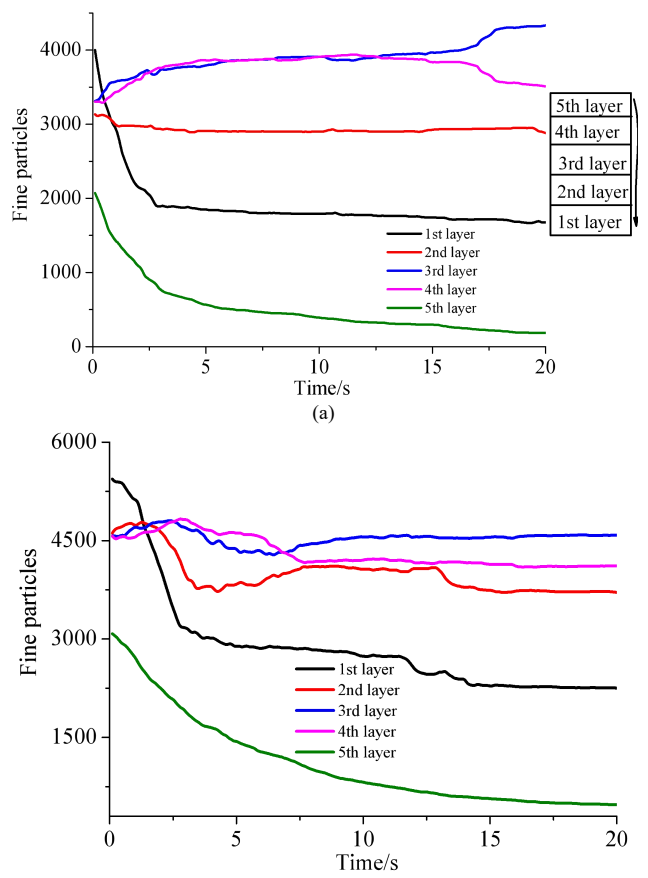

(b)

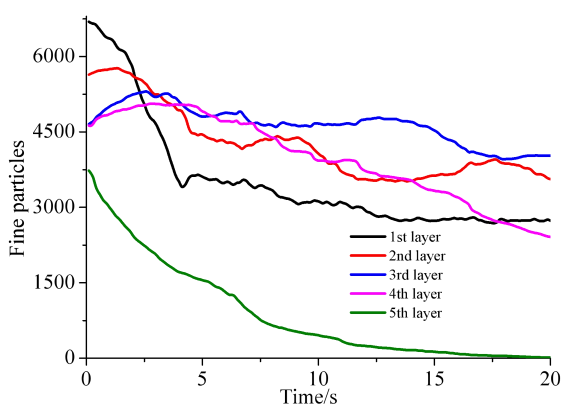

(c)

Figure 13 Number of fine particles at different heights: (a) $\mathrm{FC}=30 \%$; (b) $\mathrm{FC}=35 \%$; (c) $\mathrm{FC}=40 \%$ 


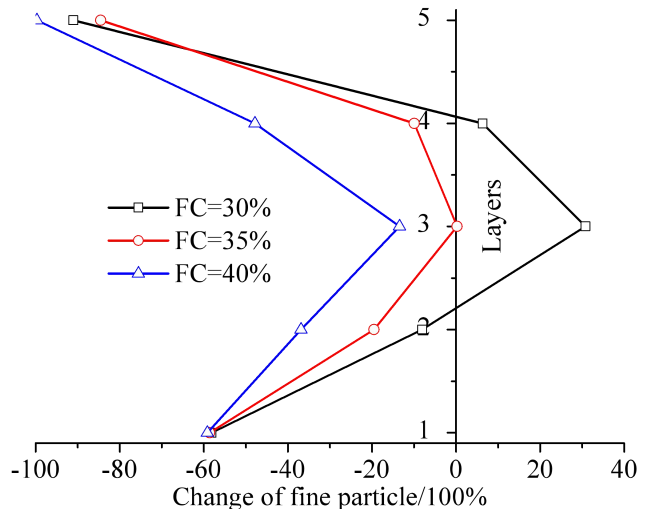

Figure 14 Vertical profile of mass loss of fine particles 


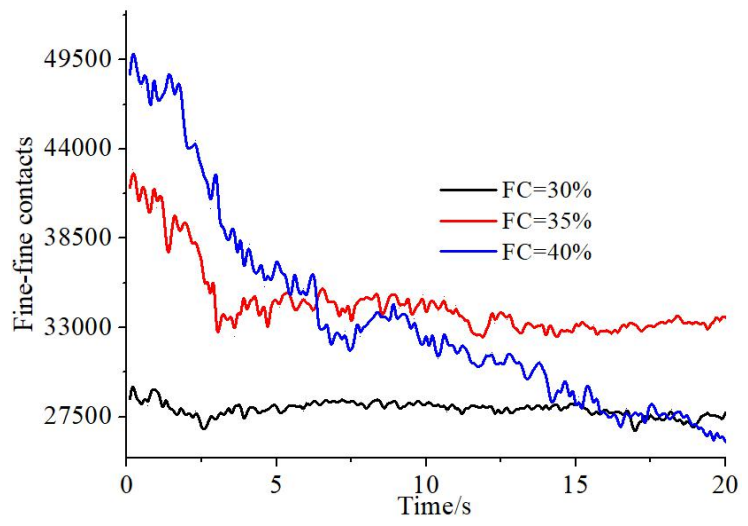

(a)

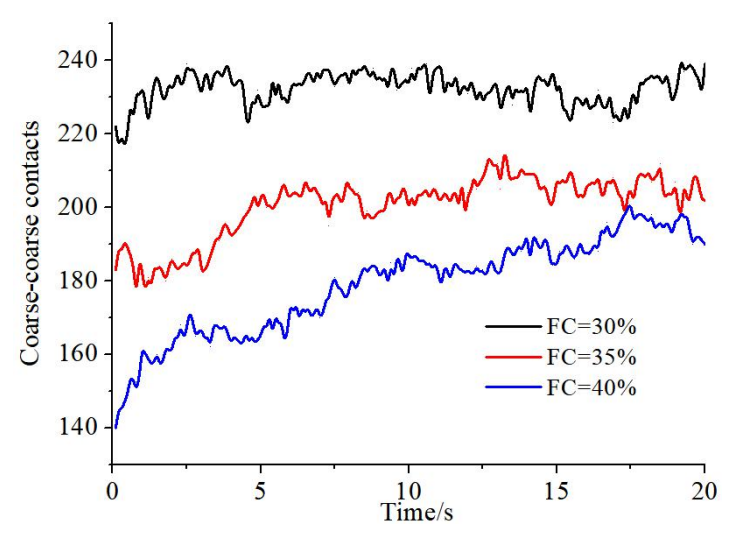

(b)

Figure 15 Change of contacts: (a)Fine-fine contact; (b)Coarse-coarse contact 

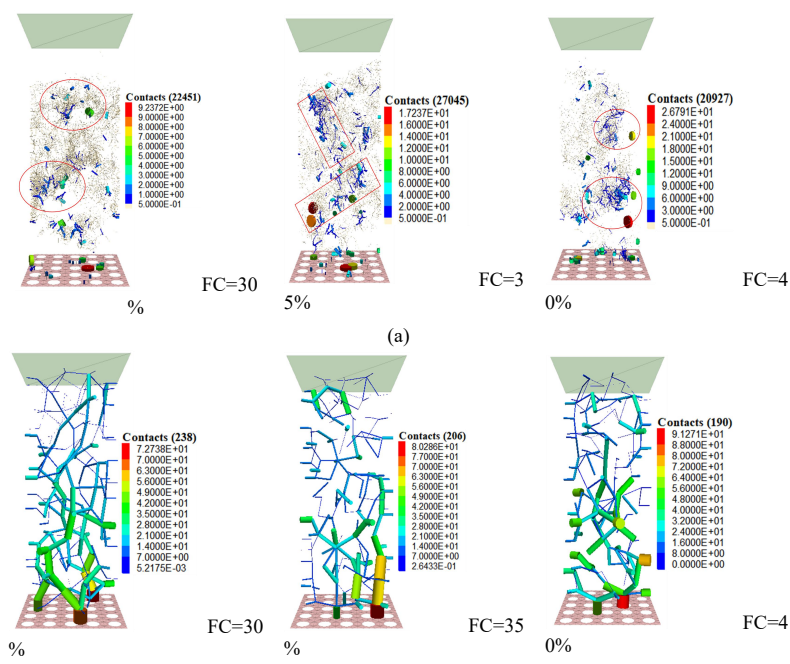

(b)

Figure 16 Load-bearing skeleton after test: (a)Fine-fine contact; (b)Coarse-Coarse contact 

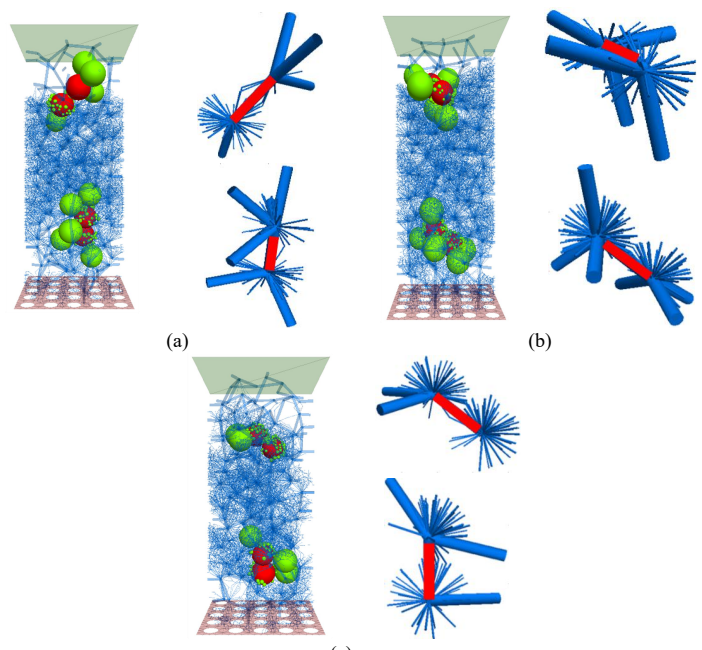

Figure 17 Particles profile and contact force chain of local packing after test: (a) $\mathrm{FC}=30 \%$; (b) $\mathrm{FC}=35 \%$; (c) $\mathrm{FC}=40 \%$ 

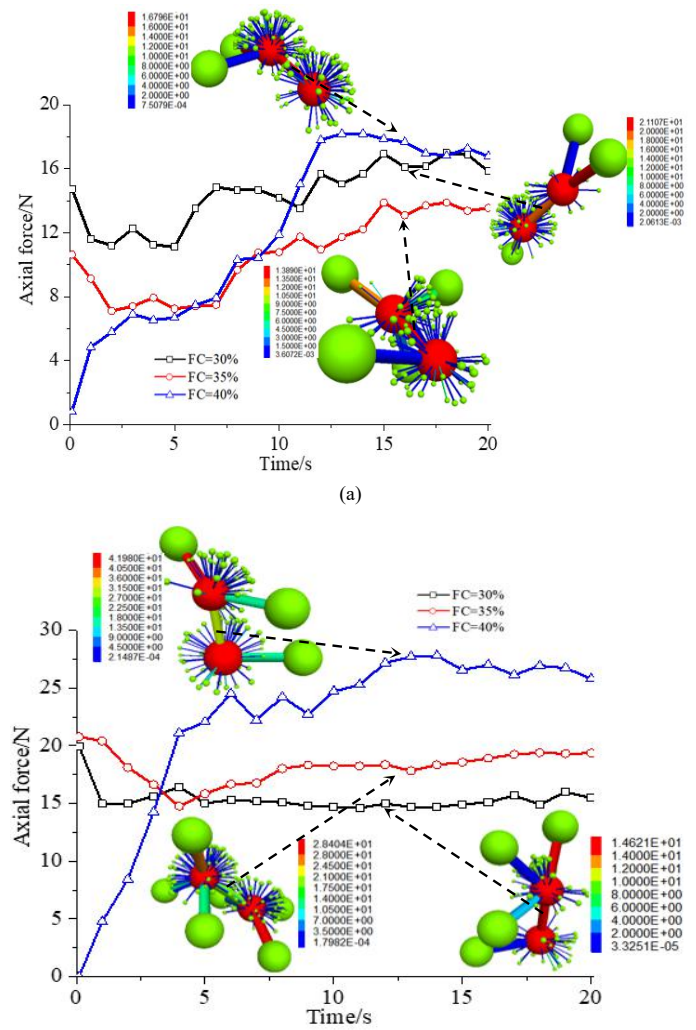

Figure 18 Evolution characteristics of the force chain for the samples with different FC: (a) upper part; (b)lower part 